\title{
Half-scale experimental study of rockfall impacts on sandy slopes
}

\author{
V. Labiouse ${ }^{1}$ and B. Heidenreich ${ }^{2, *}$ \\ ${ }^{1}$ Swiss Federal Institute of Technology Lausanne EPFL, Rock Mechanics Laboratory LMR, Station 18, \\ 1015 Lausanne, Switzerland \\ ${ }^{2}$ Lombardi AG, Winkelriedstr. 37, 6003 Luzern, Switzerland \\ * formerly at: Swiss Federal Institute of Technology Lausanne EPFL, Rock Mechanics Laboratory LMR, \\ 1015 Lausanne, Switzerland
}

Received: 19 February 2009 - Revised: 28 September 2009 - Accepted: 5 October 2009 - Published: 3 December 2009

\begin{abstract}
In the framework of rockfall trajectory modelling, the bouncing phenomenon occurring when a rock block impacts with the slope surface is the most difficult to predict, owing to its complexity and its very limited understanding. To date, the rebound is commonly quantified by means of two coefficients of restitution estimated from a rough description of the ground material. To acquire a better knowledge of the bouncing phenomenon and to investigate the influence of various impact parameters, a comprehensive experimental study was undertaken at the LMR-EPFL (Rock Mechanics Laboratory - Swiss Federal Institute of Technology Lausanne).

After a summary of the main conclusions drawn from a small-scale study, the paper focuses on half-scale experiments, describing first the testing device and the data processing and analysing then the influence of several impact parameters. It is observed that the rebound and the commonlyused coefficients of restitution expressed for the mass centre of the block depend not only on slope material characteristics, but also on factors related to the kinematics (slope inclination and impact velocity) and to the block (weight, size and shape). As many trajectory computer codes consider constant coefficients of restitution only function of the outcropping material, the trajectory results should be interpreted with caution and always checked against field observations.
\end{abstract}

\section{Introduction}

Rockfalls are a major hazard in densely populated mountain areas, such as the Alps. It is particularly important in these areas to have the best possible knowledge of rockfall trajectories (in particular maximum path length, height and

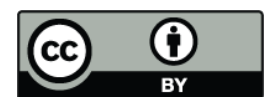

Correspondence to: V. Labiouse (vincent.labiouse@epfl.ch) velocity) and energies in order to determine the areas at risk and construct adequate protection measures. On condition of correct calibration, computer programs can be considered as valuable tools for quantitative analyses of block trajectories. They usually distinguish four mechanisms of block movement: free falling, bouncing, rolling and sliding. The bouncing phenomenon occurring when a falling block impacts with the slope surface is undoubtedly the part within a trajectory which is the less understood and the most difficult to predict.

Most rockfall computer codes model the bouncing phenomenon in a simplified way by one or two overall coefficients, called the coefficients of restitution (e.g. Wu, 1985; Hungr and Evans, 1988; Pfeiffer and Bowen, 1989; Giani, 1992; Azzoni and Freitas, 1995; Stevens, 1998). The most commonly used definitions are expressed in terms of restitution for velocities or energies, indicating the amount of velocity or energy dissipated during the ground impact (Fig. 1):

$$
\begin{aligned}
& R_{n}=-\frac{V_{n}^{+}}{V_{n}^{-}} \quad \text { and } \quad R_{t}=\frac{V_{t}^{+}}{V_{t}^{-}} \\
& R_{T E}=\frac{E_{\mathrm{tot}}^{+}}{E_{\mathrm{tot}}^{-}}=\frac{m\left[\left(V_{n}^{+}\right)^{2}+\left(V_{t}^{+}\right)^{2}\right]+I\left(\omega^{+}\right)^{2}}{m\left[\left(V_{n}^{-}\right)^{2}+\left(V_{t}^{-}\right)^{2}\right]+I\left(\omega^{-}\right)^{2}}
\end{aligned}
$$

where $V$ and $\omega$ are the translational and rotational velocity respectively, $m$ is the mass and $I$ the moment of inertia about the centre of the block. The subscripts "-" and "+" characterise the velocity or energy before and after the impact, respectively.

The expressions quoted above are derived from the inelastic collision of particles in the Newtonian mechanics and generally assume a constant value of the coefficients of restitution irrespective of the impact energy. For impacts of boulders on hard rock slopes, this approach may be justified (disregarding the fragmentation of the block). For impacts on granular material, characterising most talus slopes and thus

Published by Copernicus Publications on behalf of the European Geosciences Union. 


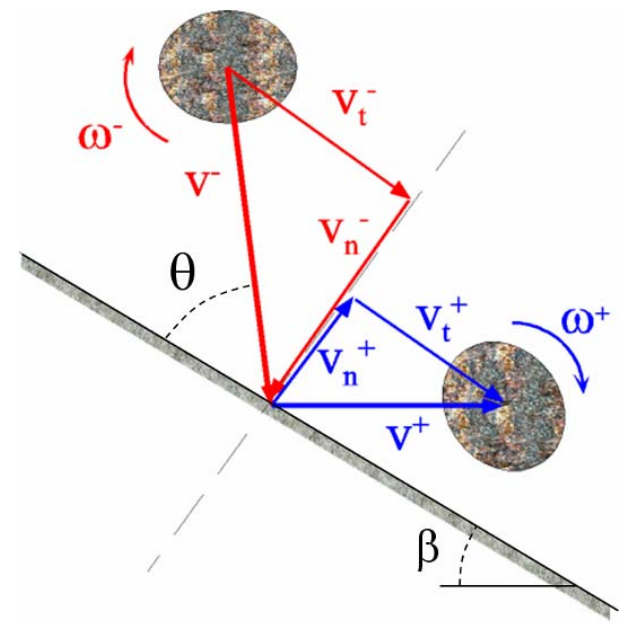

Fig. 1. Velocities of a boulder before (-) and after (+) its impact with a slope surface.

rockfall prone areas, this assumption of coefficients of restitution independent of the impact energy is highly suspicious to match reality. Indeed, plastic processes develop during the boulder penetration into the ground and therefore the energy loss depends on the block kinematics.

Usually, the restitution coefficients used for trajectory calculations are estimated based on a rough description of the slope material (e.g. rock, scree, loose soil) and sometimes completed by information regarding its roughness, its compaction degree, and the vegetation cover (including trees). However, as mentioned by several authors (e.g. Azimi et al., 1982; Falcetta, 1985; Bozzolo and Pamini, 1986; Hungr and Evans, 1988; Barbieri et al., 1988; Giani, 1992; Azzoni and Freitas, 1995; Gerber, 1995; Dorren et al., 2006) who have experienced natural and/or artificial in situ rockfalls, the analysis of impacts shows that the characteristics of motion after impact are affected not only by the slope characteristics (including the forest), but also by several parameters related to the block as well as to the kinematics during impact (Table 1).

In order to better understand the bouncing phenomenology of blocks and to determine the most important parameters influencing the impact, systematic laboratory experimental investigations have been carried out on small- and mediumscale models. Indeed, the impact conditions are easy to control and repeatable, as these requirements are often difficult to fulfil on site. It is beyond the scope of this paper to review all the investigations performed to date to analyse the impact phenomenon and the parameters that influence the rebound. Table 2 presents some references of studies and their main conclusions about the influence on the coefficients of restitution of parameters related to the block, the ground and the kinematics. The trends are illustrated by arrows, pointing up for increasing values and pointing down for decreasing values. In some cases, the trend is not clear or even contradictory.
Table 1. Parameters assumed to influence the bouncing phenomenon (Labiouse and Descoeudres, 1999).

\begin{tabular}{|c|c|c|}
\hline $\begin{array}{l}\text { Slope } \\
\text { characteristics }\end{array}$ & $\begin{array}{l}\text { Block } \\
\text { characteristics }\end{array}$ & Kinematics \\
\hline $\begin{array}{l}\text { strength, } \\
\text { stiffness, } \\
\text { roughness, } \\
\text { inclination, }\end{array}$ & $\begin{array}{l}\text { strength, } \\
\text { stiffness, } \\
\text { weight, } \\
\text { size, } \\
\text { shape, }\end{array}$ & $\begin{array}{l}\text { velocity (translational } \\
\text { and rotational), } \\
\text { collision angle, } \\
\text { configuration of } \\
\text { the block at impact }\end{array}$ \\
\hline
\end{tabular}

For what concerns characteristics of the block, its mass is found to have an influence on the normal coefficient of restitution (Ushiro et al., 2000) and its shape on all three coefficients of restitution (Wong et al., 2000; Chau et al., 1999a). The influence of the boulder shape is very tricky to quantify because it depends on the ground material, the impact angle $\theta$ (see Fig. 1 for definition) and the configuration of the block at impact. As for the outcropping material, it is generally agreed on a clear influence of its stiffness on the rebound (Pfeiffer and Bowen, 1989; Fornaro et al., 1990; Chau et al., 2002; Wu, 1985). For soft ground material (Chau et al., 1999b), the dry density appears to play as well a role, depending on the water content $w$ (compared to the optimal water content $w_{\text {opt }}$ ), but this can be related to the degree of compaction of the soil and accordingly to its Young's modulus. Experiments emphasise also a clear dependency of the coefficients of restitution on parameters characterising the kinematics as the impact velocity (Urciuoli, 1988; Ushiro et al., 2000), the impact angle $\theta$ and/or the slope inclination $\beta$ (Wu, 1985; Wong et al., 2000; Chau et al., 2002). Those studies point out that the more normal the impact is to the slope surface (increasing impact angle $\theta$, see Fig. 1), the less the block rebounds. Note that, as all experiments consisted in vertical drops on inclined slopes, the impact angle $\theta$ and the slope inclination $\beta$ complete each other to $90^{\circ}$.

The gathered knowledge is mainly based on impact tests on hard ground materials (e.g. rock, concrete or plaster). Surprisingly few investigations deal with soft ground material. For that reason, a Ph.D. thesis at the Rock Mechanics Laboratory (LMR) of the Swiss Federal Institute of Technology Lausanne (EPFL) aimed at acquiring a better knowledge of the bouncing phenomenon of rock blocks on soft ground materials and to investigate the influence of various impact parameters (Heidenreich, 2004). A small-scale experimental study was first undertaken to determine the most important parameters for impacts on granular slopes (Heidenreich and Labiouse, 2004). Then, due to the difficulty in matching the scaling laws, a half-scale testing study was completed to quantify the coefficients of restitution. After a summary of the main conclusions drawn from the small-scale study, the paper will focus on the half-scale experiments, describing 
Table 2. Summary of the parameters influencing the coefficients of restitution and the corresponding trends stated in literature. The arrows $\nearrow$ and $\searrow$ indicate respectively an increase or decrease of the coefficient of restitution related to an increase of the parameter in the first column. $\leftrightarrow$ means that no significant effect was observed.

\begin{tabular}{|c|c|c|c|c|c|c|}
\hline \multicolumn{2}{|r|}{ Parameter } & $\mathrm{R}_{\mathrm{n}}$ & $\mathrm{R}_{\mathrm{t}}$ & $\mathrm{R}_{\mathrm{TE}}$ & $\begin{array}{l}\text { Ground } \\
\text { material }\end{array}$ & reference \\
\hline \multirow{3}{*}{$\frac{\frac{y}{O}}{n}$} & Block mass $\nearrow$ & $\searrow$ & & & $\begin{array}{c}\text { Concrete, } \\
\text { rock }\end{array}$ & Ushiro et al., 2000 \\
\hline & \multirow{2}{*}{$\begin{array}{l}\text { Angularity } \nearrow \\
\text { (shape changing } \\
\text { from sphere to } \\
\text { angular block) }\end{array}$} & $\searrow$ & $\begin{array}{c}\lambda \\
\text { (slightly) }\end{array}$ & 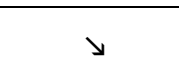 & Granite & Wong et al., 2000 \\
\hline & & $\begin{array}{l}30^{\circ}<\theta<60^{\circ}:- \\
15^{\circ}<\theta<30^{\circ}:\end{array}$ & $\begin{array}{c}\searrow \\
\text { (slightly) }\end{array}$ & $\begin{array}{c} \\
\text { (slightly) }\end{array}$ & Plaster & Chau et al., 1999a \\
\hline \multirow{4}{*}{$\begin{array}{l}\vec{E} \\
\bar{\Xi} \\
\overline{0}\end{array}$} & \multirow{3}{*}{$\begin{array}{l}\text { Young's } \\
\text { Modulus } \nearrow\end{array}$} & $\pi$ & $\pi$ & & $\begin{array}{c}\text { Natural } \\
\text { slopes }\end{array}$ & $\begin{array}{c}\text { Pfeiffer and } \\
\text { Bowen, } 1989\end{array}$ \\
\hline & & $\pi$ & $\pi$ & & $\begin{array}{c}\text { Natural } \\
\text { slopes }\end{array}$ & Fornaro et al., 1990 \\
\hline & & $\pi$ & $\pi$ & & $\begin{array}{l}\text { Plaster, } \\
\text { rock, soil }\end{array}$ & $\begin{array}{c}\text { Chau et al., } 2002 \\
\text { Wu, } 1985\end{array}$ \\
\hline & Dry density $\nearrow$ & $\begin{array}{l}\mathrm{w}<\mathrm{w}_{\text {opt }}: \nearrow \\
\mathrm{w}>\mathrm{w}_{\text {opt }}: \leftrightarrow\end{array}$ & $\begin{array}{l}\mathrm{w}<\mathrm{w}_{\text {opt }}: \\
\mathrm{w}>\mathrm{w}_{\text {opt }}: \leftrightarrow\end{array}$ & $\begin{array}{l}\mathrm{w}<\mathrm{w}_{\text {opt }}: \\
\mathrm{w}>\mathrm{w}_{\text {opt }}: \stackrel{\leftrightarrow}{ }\end{array}$ & $\begin{array}{l}\text { Soil, } \\
\text { plaster }\end{array}$ & Chau et al., 1999b \\
\hline \multirow{7}{*}{ 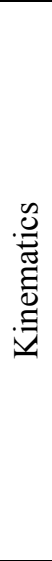 } & \multirow{5}{*}{$\begin{array}{c}\text { Impact angle } \theta \nearrow \\
\text { respectively } \\
\text { Slope angle } \beta \text { У }\end{array}$} & ע & $\begin{array}{c}\lambda \\
\text { (slightly) }\end{array}$ & & $\begin{array}{l}\text { Wood, } \\
\text { rock }\end{array}$ & $\mathrm{Wu}, 1985$ \\
\hline & & $\begin{array}{c}\searrow \\
\text { (slightly) }\end{array}$ & & & $\begin{array}{l}\text { Granite, } \\
\text { shotcrete }\end{array}$ & \multirow{2}{*}{ Wong et al., 2000} \\
\hline & & 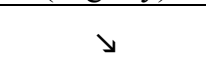 & & & $\begin{array}{l}\text { Plaster, } \\
\text { soil }\end{array}$ & \\
\hline & & $\begin{array}{c} \\
\text { (slightly) }\end{array}$ & $\leftrightarrow$ & ע & $\begin{array}{l}\text { Granite, } \\
\text { shotcrete }\end{array}$ & \multirow{2}{*}{ Chau et al., 2002} \\
\hline & & ע & $\leftrightarrow$ & 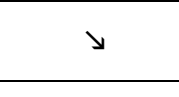 & $\begin{array}{c}\text { Plaster, } \\
\text { soil }\end{array}$ & \\
\hline & \multirow{2}{*}{$\begin{array}{l}\text { Drop height } \mathrm{H} \\
\text { respectively } \\
\text { Impact velocity }\end{array}$} & y & ע & ע & Limestone & Urciuoli, 1988 \\
\hline & & $\begin{array}{c} \\
\text { (slightly) }\end{array}$ & $\leftrightarrow$ & & $\begin{array}{c}\text { Concrete, } \\
\text { rock }\end{array}$ & Ushiro et al., 2000 \\
\hline
\end{tabular}

first the testing device and the data processing and analysing then the influence of impact parameters related to the slope (inclination), the block (weight, size and shape) and the kinematics (falling height).

\section{Small-scale experimental study}

Prior to the half-scale experiments presented in Sect. 3, small-scale impact experiments were carried out as preliminary study to get a first understanding of the bouncing mechanism, to determine the most important parameters and to help to define the half-scale experimental study.

The set-up (Fig. 2) consisted of an inclinable box containing soil, two different block-releasing devices for vertical and inclined impacts and a numerical high-speed camera. Spherical blocks with a diameter of $7.5 \mathrm{~cm}$ and different weights are dropped on different granular materials at a speed of about $4.4 \mathrm{~m} / \mathrm{s}$, which corresponds to one meter of free fall. The camera is installed perpendicularly to the block motion plane and captures the impact at an operating speed of 250 frames per second (Heidenreich and Labiouse, 2003, 2004). Approximately 210 impacts were carried out to investigate the influence of parameters relative to ground, block and kinematics (Table 3).

To allow the motion analysis of the blocks by means of only one camera, the testing conditions were such that the trajectories before and after impact were lying in the same plane, i.e. the vertical plane perpendicular to the ground surface. This was checked after each impact based on the traces left by the block on the ground. By means of an image processing software, the motion of the boulders was analysed and the velocities (translational and rotational) before and after the impact determined. The normal $\left(R_{n}\right)$, tangential $\left(R_{t}\right)$ and energetic $\left(R_{T E}\right)$ coefficients of restitution were then evaluated for the mass centre of the block, as the ratio of the normal or tangential velocities of the centre of mass respectively the total energy before and after impact. 

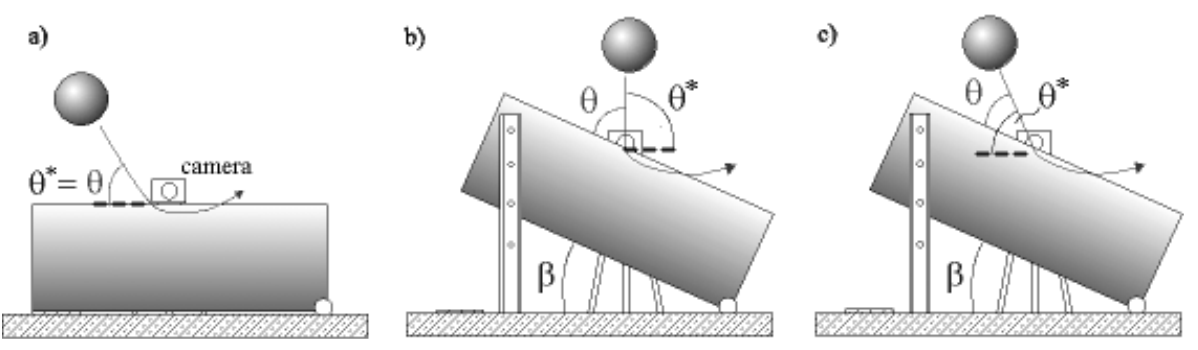

Fig. 2. Experimental set-up for small-scale tests. Inclined fall on horizontal soil (a), vertical fall on inclined soil (b) and inclined impact on inclined ground (c).

Table 3. Parameters explored in the small-scale experimental study.

\begin{tabular}{lll}
\hline & Parameter & Set of values/cases \\
\hline Ground (granular material) & $\begin{array}{l}\text { friction angle } \\
\text { degree of compaction } \\
\text { slope inclination } \beta\end{array}$ & $\begin{array}{l}32^{\circ}, 35^{\circ}, 43^{\circ} \\
\text { compacted or bulked } \\
0^{\circ}, 12^{\circ}, 22^{\circ}, 32^{\circ}\end{array}$ \\
weight & $130,380,750 \mathrm{~g}$ \\
Kinematics (motion in the vertical plane & $\begin{array}{l}\text { impact angle } \theta \\
\text { perpendicular to the slope surface) }\end{array}$ & $\begin{array}{l}90^{\circ}, 78^{\circ}, 68^{\circ}, 58^{\circ} \\
\text { imclined fall on horizontal soil, vertical fall on inclined soil } \\
\text { and inclined impact on inclined ground (respectively cases a, } \\
\text { b, and c in Fig. 2) }\end{array}$ \\
\hline
\end{tabular}

The analysis and comparison of the results from the different testing series allowed the determination of the most significant parameters. Full discussion of these results is reported by Heidenreich and Labiouse (2004). The main conclusions drawn from this investigation work are:

- Concerning the slope material characteristics, the motion of the block during and after impact is moderately influenced by the friction angle and significantly by the degree of compaction (i.e. modulus of deformation).

- Concerning the block characteristics, testing series performed with spheres of identical diameter but of different weight show a certain decrease of the rebound and consequently of the coefficients of restitution for increasing block weights.

- The experiments also emphasise a clear dependency of the coefficients of restitution on parameters characterising the kinematics as the slope inclination and the impact angle: similar to observations made for impacts on rock slopes, the block rebounds less the more normal the impact on the slope surface. The more tangent the impact is relative to the slope surface, the more distinct the rotation of the block after impact.

\section{Half-scale experimental study}

The small-scale experiments have been helpful for better understanding the impact phenomenon and defining the most important parameters. However, a dimensional analysis has pointed out the difficulty in matching the similitude requirements (scaling laws) for all the parameters involved in the impact process (Heidenreich, 2004). This is particularly hard for the modulus of deformation of the soil, which was precisely found to significantly affect the rebound of the blocks. A quantitative interpretation of the small-scale experiments is thus not appropriate. Consequently, a half-scale experimental study has been carried out to verify the qualitative conclusions drawn from the small-scale tests and, above all, to quantify the influence of the various impact parameters as well as to develop mathematical formulations to express the coefficients of restitution.

The term "half-scale" is chosen to emphasise the fact that the size and weight of the blocks ( $\max .10 \mathrm{kN})$ and the impact energy (up to $100 \mathrm{~kJ}$ ) of the tests can be compared to natural low-energy events but still do not match the energy scale of bigger natural rockfall events.

\subsection{Testing device}

The half-scale experiments are carried out in a shaft with a diameter of $5 \mathrm{~m}$ and a depth of $8 \mathrm{~m}$ (Fig. 3). Blocks of different weights (up to $10 \mathrm{kN}$ ) and shape are dropped vertically 


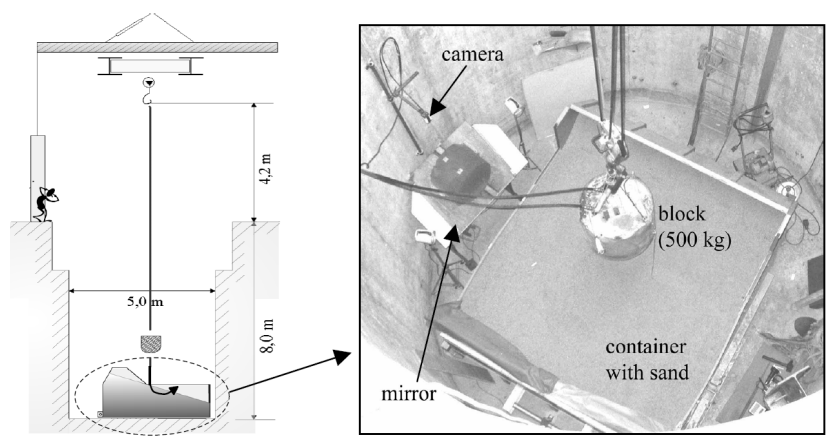

Fig. 3. Scheme (left) and picture (right) of the half-scale testing device.

from various heights (up to $10 \mathrm{~m}$ ) on a horizontal or inclined layer of sand (inclination up to $30^{\circ}$ ). The thickness of the sand layer beneath the impact point was kept constant at $1 \mathrm{~m}$ throughout the experimental study.

The ground material is a well graded sand from deposits of the Geneva Lake with grain sizes between 0.1 and $4 \mathrm{~mm}$ (SW according to the USCS classification). Its friction angle amounts to $33^{\circ}$. It was poured into a container and the ground surface was slightly compacted by means of a vibrating plate. After each impact, the ground was prepared for the next test by refilling the crater, compacting it in layers by stamping and finally flattening it with a rake. Obviously, a certain dynamic ground compaction was observed with ongoing series, but the upper soil layer (up to $0.4 \mathrm{~m}$ depth) was found to remain very loose (i.e. dynamic cone resistance measured with a PANDA sounding device lower than $1 \mathrm{MPa}$ ).

The first set of blocks has already been used for previous impact tests on a rock-shed model (Labiouse et al., 1996; Montani Stoffel, 1998). The blocks are made of a steel shell filled with concrete. The shape is cylindrical with a spherical base (see Table 4 and Fig. 4). All three blocks have a constant ratio between the mass of the cylindrical section and the total block mass. The ratio between the height and the diameter of the cylindrical section is constant as well. Additionally a second set of purely spherical blocks is used. They also consist of a steel shell and all but one are filled with concrete. The diameter of the spherical blocks is chosen to match that of the cylindrical blocks.

175 impact tests were performed and organised in series to systematically isolate and investigate the influence of parameters related to the ground (slope inclination), to the block (weight, size and shape) and to the kinematics (falling height). To check the repeatability of the tests and to estimate the variability of the results, three impacts are realised and analysed for each combination of parameters.
Table 4. Characteristics of the blocks used for the half-scale experimental study.

\begin{tabular}{|c|c|c|c|c|}
\hline $\begin{array}{l}\text { Block } \\
\text { shape }\end{array}$ & $\begin{array}{r}\text { Block } \\
\text { mass } \\
m[\mathrm{~kg}]\end{array}$ & $\begin{array}{r}\text { Unit } \\
\text { weight } \\
\gamma\left[\mathrm{kN} / \mathrm{m}^{3}\right]\end{array}$ & $\begin{array}{r}\text { Diameter } \\
\qquad D[\mathrm{~m}]\end{array}$ & $\begin{array}{l}\text { Radius } \\
R \text { or } r[\mathrm{~m}]\end{array}$ \\
\hline $\mathrm{R}$ & $\begin{array}{r}100 \\
500 \\
1000\end{array}$ & $\begin{array}{l}25.8 \\
25.6 \\
26.2\end{array}$ & $\begin{array}{l}0.42 \\
0.72 \\
0.90\end{array}$ & $\begin{array}{l}R=0.30 \\
R=0.52 \\
R=0.60\end{array}$ \\
\hline & $\begin{array}{l}117 \\
152 \\
553\end{array}$ & $\begin{array}{r}30.1 \\
7.5 \\
27.1\end{array}$ & $\begin{array}{l}0.42 \\
0.73 \\
0.73\end{array}$ & $\begin{array}{l}r=0.21 \\
r=0.365 \\
r=0.365\end{array}$ \\
\hline
\end{tabular}
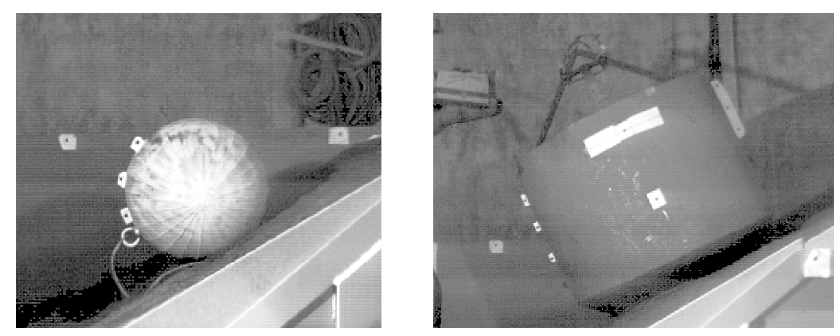

Fig. 4. Targets fixed on the sides of the blocks. Sphere on the left and cylinder with a spherical base on the right.

\subsection{Data acquisition and processing}

As for the small-scale tests, the motion of the blocks is in a vertical plane perpendicular to the ground surface and is captured by means of a high speed camera at an operating speed of 250 frames/s. However, for lack of space in the shaft, a wide-angle lens had to be used to film the impact. The resulting radial distortion had to be corrected prior to the motion analysis to avoid miscalculations of the position, velocity and acceleration of the blocks (details are provided in Heidenreich, 2004). Moreover, to avoid measurement errors due to targets not in the same plane as the block centre, the targets were fixed on the sides of the blocks so that they are in the same moving plane as the centre of mass (Fig. 4). The motion was analysed by an image processing software (WINanalyze) which tracks automatically the targets fixed on the block. It allows to compute their successive positions and then to determine the velocities and energies of the block at any time before, during and after the impact.

In Eqs. (1) and (2), the evaluation of the restitution coefficients is based on the motion characteristics of the mass centre of the boulder before and after its impact with the slope, which thus necessitates the determination of the beginning and the end of the impact. The beginning of the impact is easily detected by a careful frame-by-frame analysis of the film, 

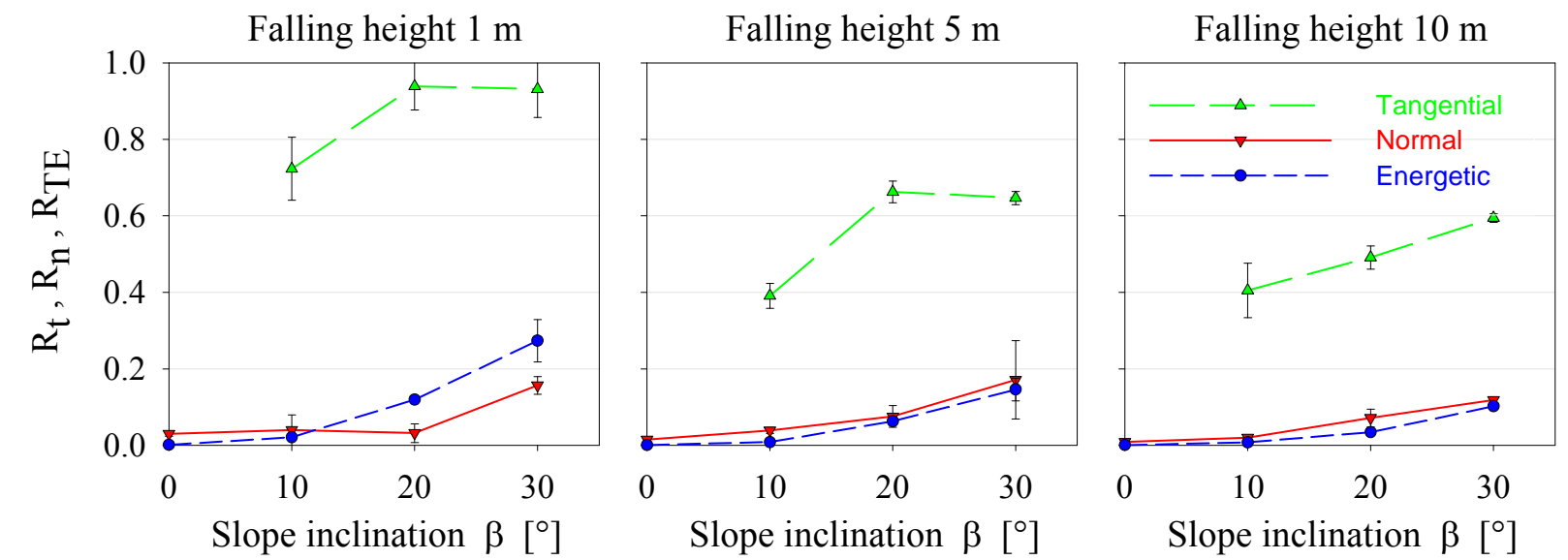

Fig. 5. Impacts of the $1000 \mathrm{~kg}$ cylindrical block. Dependency of the coefficients of restitution (normal $R_{n}$, tangential $R_{t}$ and energetic $R_{T E}$ ) on the slope inclination and the falling height (increasing from the left to the right diagrams).

observing the time when the boulder gets in contact with the ground surface. On the contrary, the end of the impact cannot be determined visually due to the throwout of ground particles and a generally indistinct rebound of the block (no complete free flight after impact). To solve this point, the normal component of the block acceleration is plotted as a function of time and, according to the theory of impacts, the end of the impact is defined as the time when it reaches the value of zero. After the determination of the times before and after impact and the corresponding incoming and rebounding velocities and energies, the coefficients of restitution $R_{t}, R_{n}$ and $R_{T E}$ can be computed according to the Eqs. (1) and (2).

\subsection{Parametrical study}

The half-scale tests confirm the results of the former smallscale tests (Heidenreich and Labiouse, 2004) and show a clear dependency of the coefficients of restitution on parameters related to the ground (slope inclination), the block (weight, size and shape) and the kinematics (falling height or energy). In the following, the influence of these impact parameters on the restitution coefficients is investigated, changing one parameter at once.

\subsubsection{Slope inclination}

In the half-scale experiments, the block impacts the ground with a purely vertical velocity after a vertical free fall. Therefore, the impact angle $\theta$ and the slope inclination $\beta$ (defined in Fig. 1) complete each other to $90^{\circ}$ and their relative influence can not be analysed. All test series reveal for each block and each falling height a clear increase of the normal $R_{n}$ and total energy $R_{T E}$ coefficients of restitution for increasing slope inclinations $\beta$. In contrast, the tangential component $R_{t}$ does not warrant a clear trend (Fig. 5). The increase of $R_{T E}$ and $R_{n}$ means that for steeper slopes (eventually near their limit of equilibrium) the block loses less energy dur- ing impact and rebounds relatively more normal to the slope surface. These trends confirm the observations made in the former small-scale experiments as well as by other authors (e.g. Wu, 1985; Chau et al., 2002).

A closer investigation of the trends shows for the $1000 \mathrm{~kg}$ cylindrical block dropped from a small height (Fig. 5, left) a sudden increase of the normal component of the coefficient of restitution $R_{n}$ for slope angles larger than $20^{\circ}$. As for the tangential component $R_{t}$, it increases strongly between $\beta=10^{\circ}$ and $20^{\circ}$ and then changes sharply to a constant value. Both observations gradually attenuate for higher impact velocities. As discussed in Sect. 4, the change in trends can be related to different mechanisms occurring during the impact.

Compared to cylindrical blocks, spheres have a slightly different behaviour: e.g. $R_{n}$ increases nearly linearly with slope inclinations for all falling heights and $R_{t}$ is almost constant (Fig. 6). The difference results from the shape of the blocks and will be commented in the corresponding section.

\subsubsection{Block weight and size}

The unit weight of rocks varying in a very limited range of values, field or laboratory tests with natural boulders do not allow to differentiate the respective influence of block weight and block size on the rebound phenomenon. Some tests of the experimental study aimed at analysing their influence.

The weight influence is first investigated. Figure 7 illustrates the position and velocity vectors before and after impact (in blue and red respectively) of the $152 \mathrm{~kg}$ and the $553 \mathrm{~kg}$ spheres of same diameter $(0.73 \mathrm{~m})$ dropped from two different falling heights $(1 \mathrm{~m}$ and $10 \mathrm{~m})$ on a slope inclined at $30^{\circ}$. The heavier block is observed to penetrate deeper into the ground, causing more plastic deformation to the soil and thus losing more energy during impact than a lighter block with same diameter. The higher accumulation of ground in front of the block further creates a higher resistance downhill. 

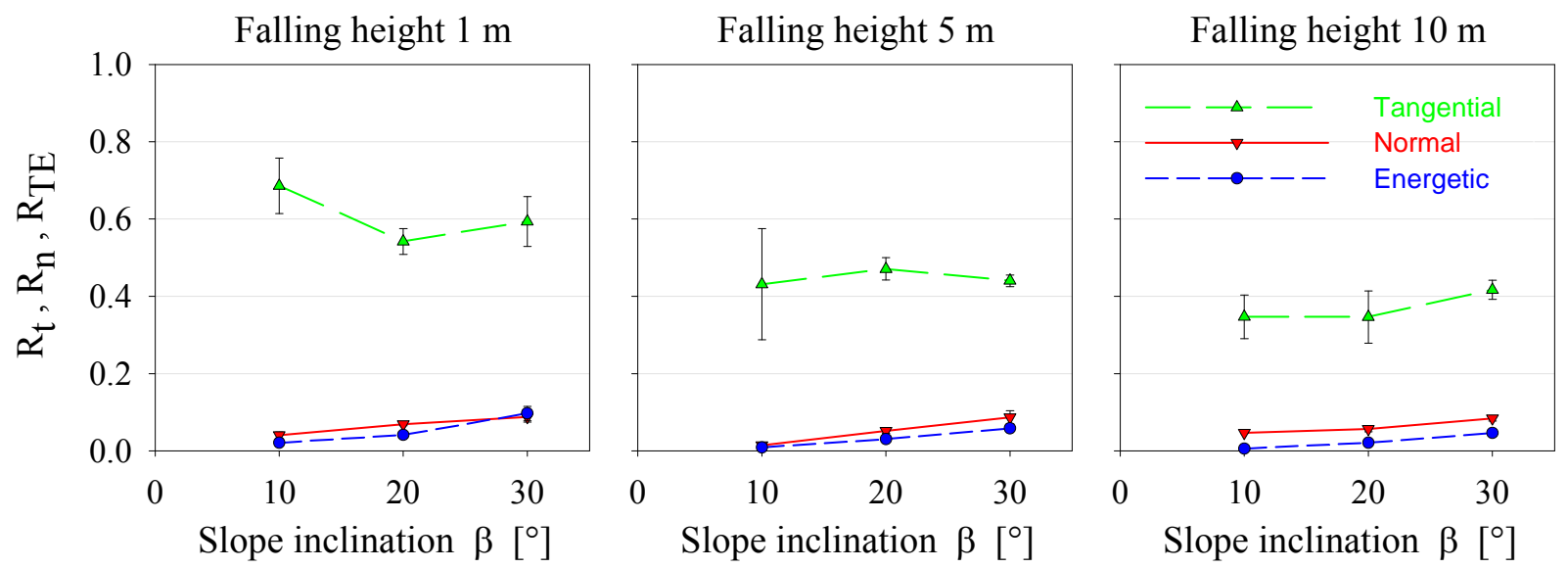

Fig. 6. Impacts of the $553 \mathrm{~kg}$ spherical block. Dependency of the coefficients of restitution (normal $R_{n}$, tangential $R_{t}$ and energetic $R_{T E}$ ) on the slope inclination and the falling height (increasing from the left to the right diagrams).
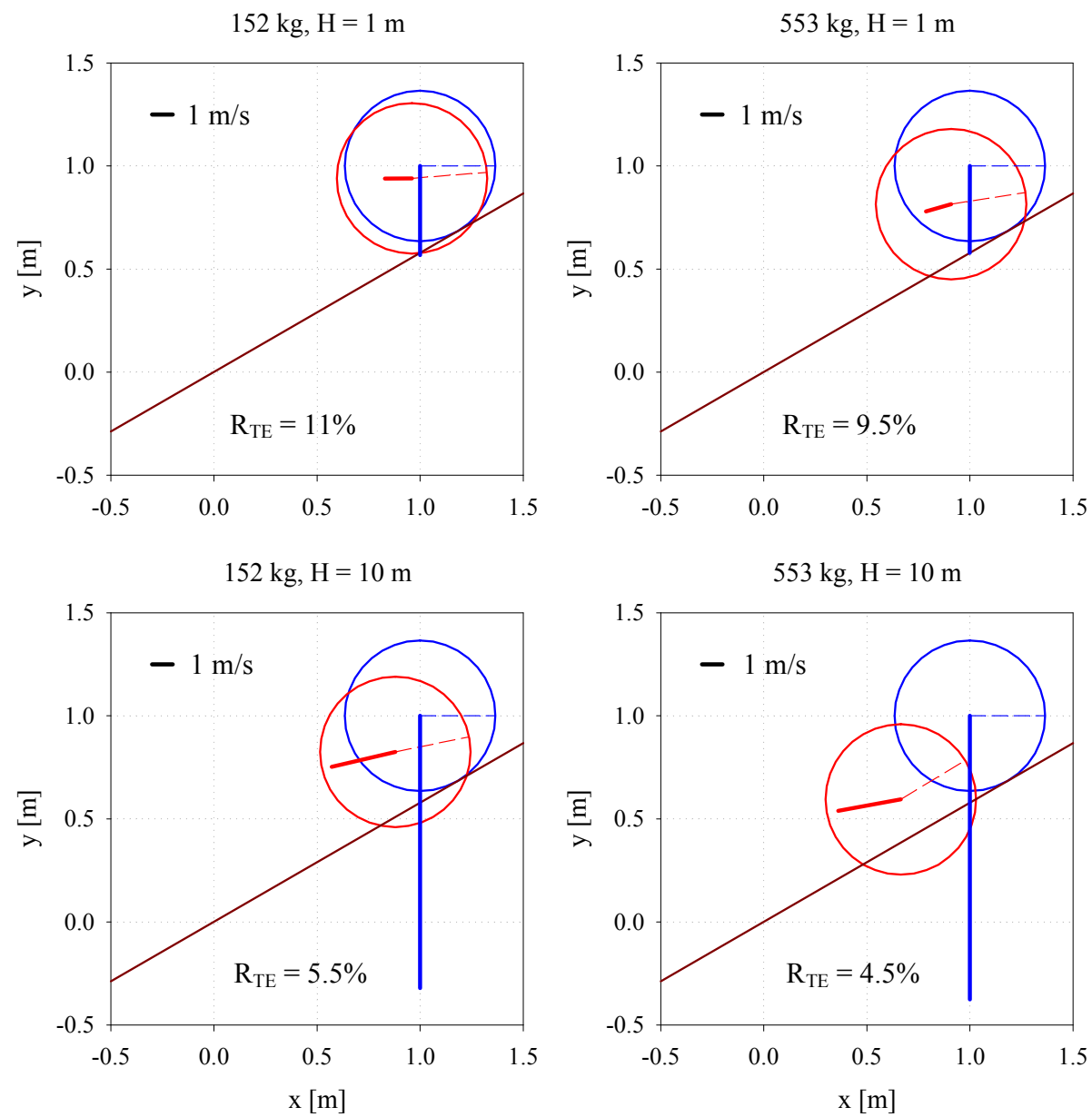

Fig. 7. Position and velocity vectors (scale in the upper left corner; blue: before impact, red: after impact) of the $152 \mathrm{~kg}$ and the $553 \mathrm{~kg}$ spheres for impact tests on a slope inclined at $30^{\circ}$ from two different falling heights (upper row: $H=1 \mathrm{~m}$, lower row: $H=10 \mathrm{~m}$ ). The energetic coefficient of restitution $R_{T E}$ is as well provided for each case. 

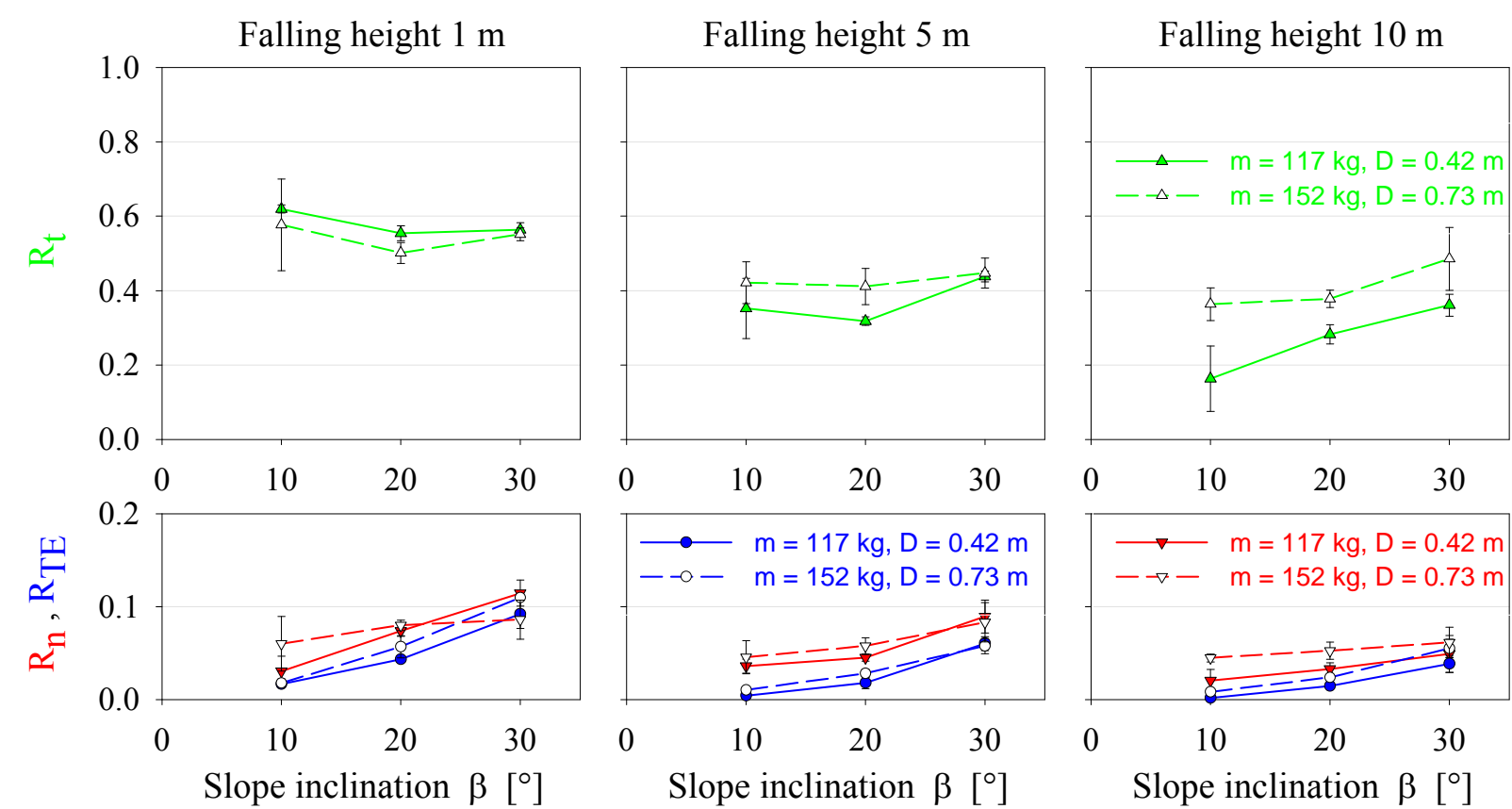

Fig. 8. Dependency of the coefficients of restitution (normal $R_{n}$, tangential $R_{t}$ and energetic $R_{T E}$ ) on the block size. Comparison between a $0.42 \mathrm{~m}$ diameter sphere $(117 \mathrm{~kg}$, solid lines) and a $0.73 \mathrm{~m}$ sphere $(152 \mathrm{~kg}$, dashed lines). The falling height is increasing from the left to the right diagrams.

However, in relative terms, the difference in energy dissipation is not significant and the energetic coefficients of restitution $R_{T E}$ are very similar for both weights (Fig. 7).

As for the influence of the block size, no straightforward comparison was possible between blocks of same weight, but different diameter. It was achieved comparing impacts of spheres of $117 \mathrm{~kg}$ and $152 \mathrm{~kg}$ (difference in weight of 30\%) with respectively diameters of $0.42 \mathrm{~m}$ and $0.73 \mathrm{~m}$ (difference of 75\%). As expected, for comparable impact conditions, it was observed that the small $117 \mathrm{~kg}$ sphere penetrates deeper into the ground during impact than the large $152 \mathrm{~kg}$ sphere. It dissipates more energy during impact and meets more ground resistance in moving direction. Consequently, in most cases (impacts with falling heights larger than $1 \mathrm{~m}$ ), the coefficients of restitution $R_{n}, R_{t}$ and $R_{T E}$ are lower for the small than for the large sphere (Fig. 8). This is valid for all slope inclinations. On the other hand, for very small impact energies (falling height of $1 \mathrm{~m}$ ), a particular trend is observed for $R_{n}$ and $R_{t}$ which can be related to an elastic response of the ground instead of a shear failure.

\subsubsection{Block shape}

Although the block shape, coupled with its configuration at impact, is known to significantly influence the rebound, few specific experiments were performed to analyse the influence of this parameter. Figure 9 compares on the left hand side the coefficients of restitution for a $1 \mathrm{~m}$ vertical drop on a $20^{\circ}$ slope of the $117 \mathrm{~kg}$ sphere and the $100 \mathrm{~kg}$ cylinder with a spherical base and on the right hand side for a $5 \mathrm{~m}$ drop of the $553 \mathrm{~kg}$ sphere and the $500 \mathrm{~kg}$ cylinder. Note that only one test was carried out for the cylinders. The energetic coefficient of restitution $R_{T E}$ is here split into its translational and rotational parts, respectively $R_{\text {Etrans }}$ and $R_{\text {Erot }}$. All coefficients of restitution are higher for the cylindrical blocks than for the spheres. Indeed, as the spherical base of the cylinders has a larger radius than the corresponding spherical block (Fig. 10), at same impact velocity the cylinder penetrates less into the ground, promoting its tangential propagation during impact (low lateral ground resistance) as well as its normal rebound velocity. Further, due to the lower penetration, less energy is dissipated during impact by plastic ground deformation. These observations are valid for slope inclinations $\beta$ larger than $10^{\circ}$.

Compared to the spheres, a higher rotation rate is observed for the cylinders with spherical base. This results from the larger eccentricity between the vertical centre line and the first contact point (Fig. 10) and from the lower lateral rolling resistance due to a smaller penetration. This rotational energy rate was found to increase with the slope inclination and no clear difference was observed between cylinders with spherical base and spheres for a slope inclination $\beta$ of $10^{\circ}$.

\subsubsection{Falling height}

Figure 11 shows the dependency of the coefficients of restitution (normal $R_{n}$, tangential $R_{t}$ and energetic $R_{T E}$ ) on the falling height for impacts on a $10^{\circ}$ inclined slope of the 

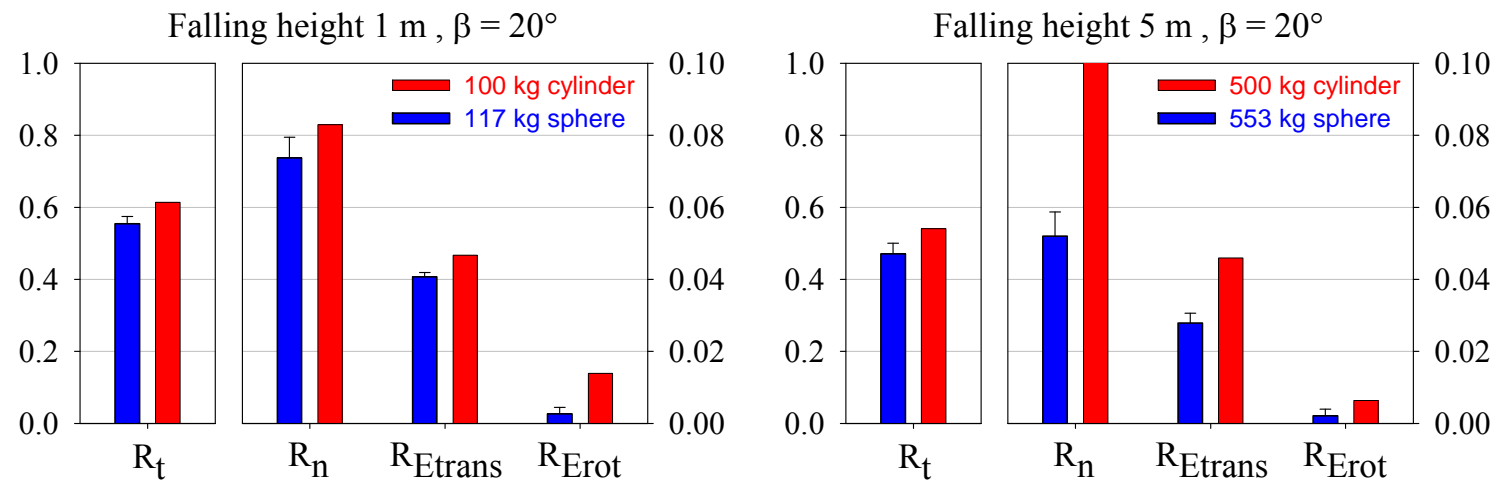

Fig. 9. Influence of block shape on the coefficients of restitution. Comparison between spheres and cylinders with a spherical base respectively plotted in blue and red. The energetic coefficient of restitution is split into its translational and rotational parts, respectively $R_{\text {Etrans }}$ and $R_{\text {Erot }}$.
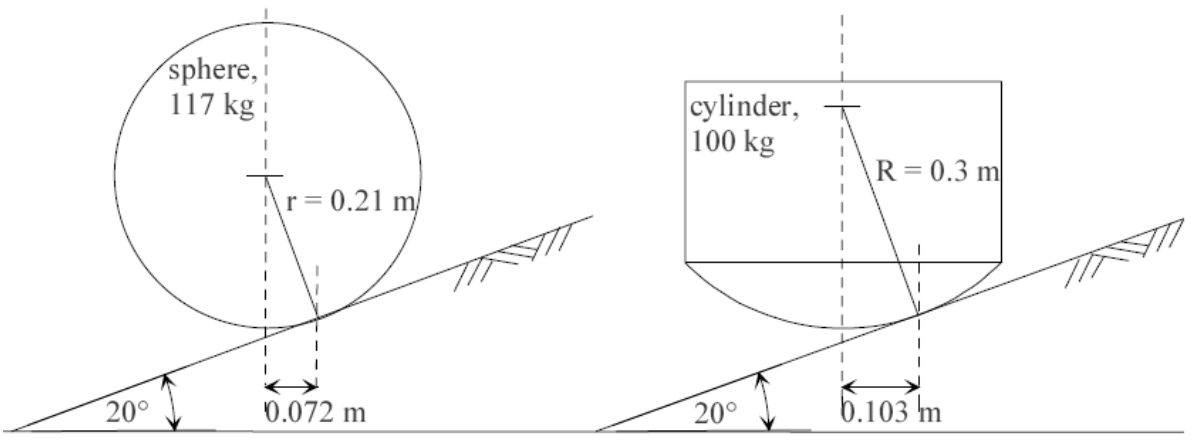

Fig. 10. Eccentricity between the vertical centre line and the first contact point with the slope for the $117 \mathrm{~kg}$ sphere and the $100 \mathrm{~kg}$ cylinder with a spherical base (illustrated for $\beta=20^{\circ}$ ).
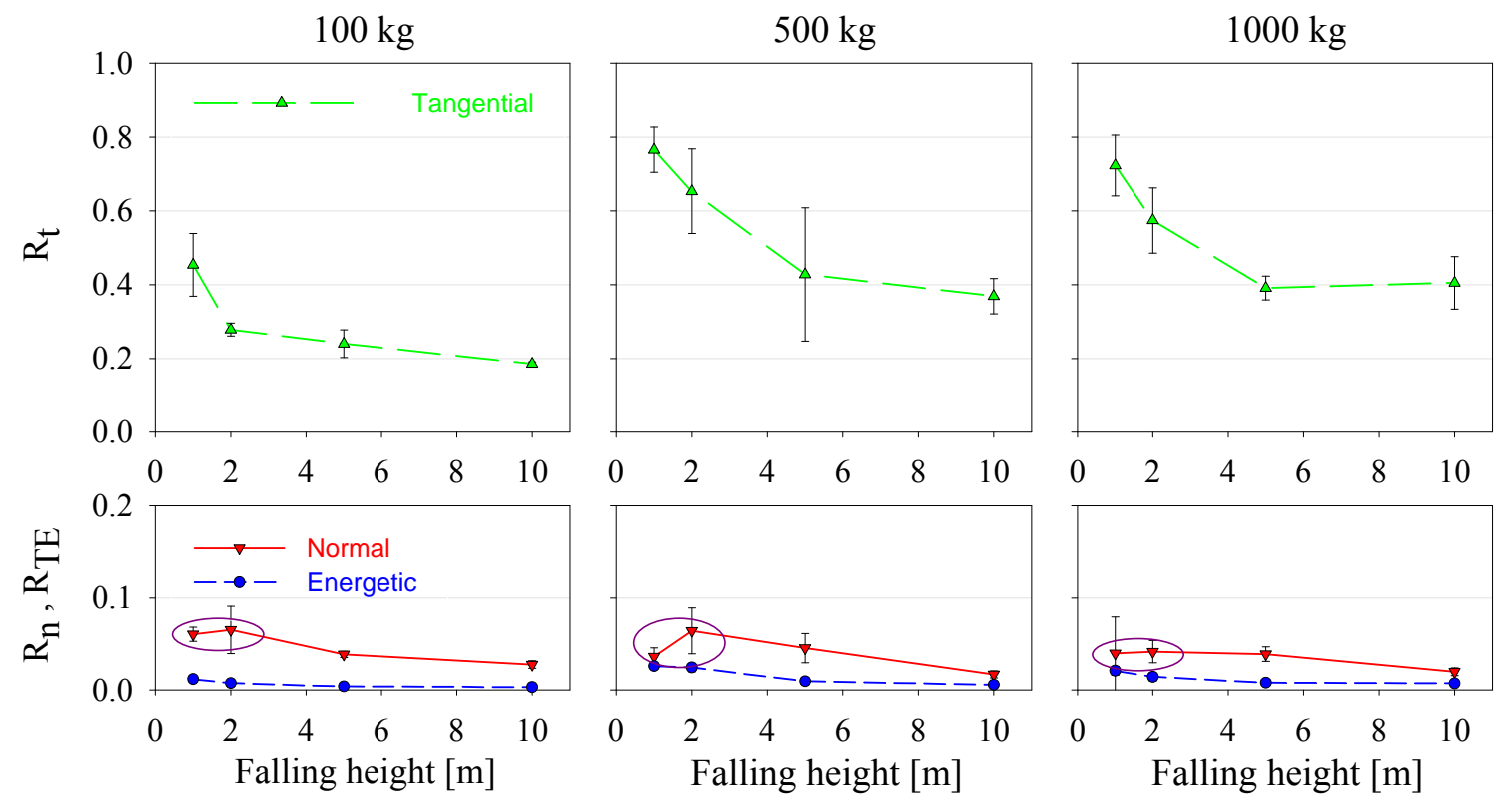

Fig. 11. Dependency of the coefficients of restitution (normal $R_{n}$, tangential $R_{t}$ and energetic $R_{T E}$ ) on the falling height for impacts of the cylindrical blocks on a $10^{\circ}$ inclined slope (block weight increasing from the left to the right diagrams, i.e. 100,500 , and $1000 \mathrm{~kg}$ ). The ovals underline the slight increasing trend for $R_{n}$ for impacts with small falling heights. 

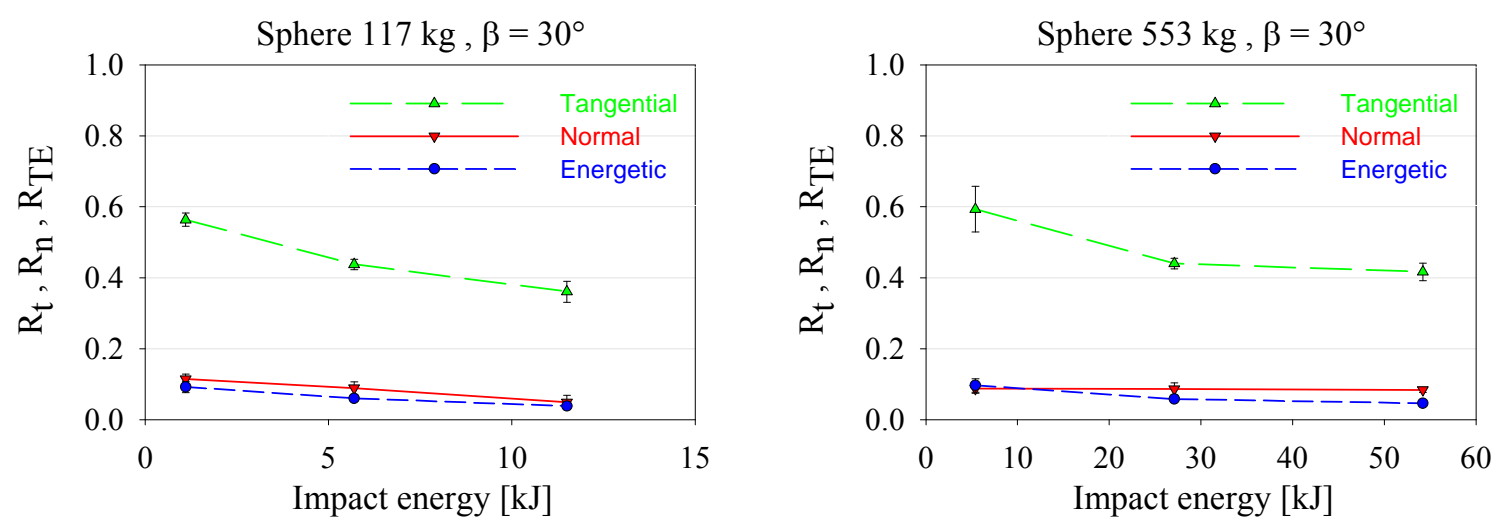

Fig. 12. Dependency of the coefficients of restitution (normal $R_{n}$, tangential $R_{t}$ and energetic $R_{T E}$ ) on the impact energy for impacts of spheres on a $30^{\circ}$ inclined slope. Attenuation of the decreasing trend of $R_{n}$ with increasing block mass $(117 \mathrm{~kg}$ on the left and $553 \mathrm{~kg}$ on the right).

cylindrical blocks $(100,500$, and $1000 \mathrm{~kg}$ from the left to the right diagrams). A very clear decrease in tangential coefficient of restitution $R_{t}$ is found for increasing falling heights, although it attenuates as the impact velocity becomes higher. In contrast, $R_{n}$ and $R_{T E}$ show in general a slighter decreasing trend. For impacts of small incident velocity, i.e. for a free fall of about $1 \mathrm{~m}$, the downhill rolling of the block is imposing the "rebound" direction. It is quite tangential to the slope surface, which means a small $R_{n}$ and a large $R_{t}$. As the falling height increases, the block is observed to penetrate deeper into the ground and then to rebound more normal to the slope because of the increasing resistance of the ground accumulated in front of it. $R_{n}$ increases slightly or remains constant and $R_{t}$ strongly decreases. Of course, the energy dissipation resulting from the ground plastification and the rolling and sliding friction increases with increasing falling heights.

The observed trend of $R_{t}$ being more sensible to the impact velocity than the normal component $R_{n}$ confirms observations made by Urciuoli (1988) and statements of other authors (e.g. Hutchings et al., 1981). A controversial observation was reported by Ushiro et al. (2000), who stated that $R_{t}$ is insensitive to the impact velocity. However, their impact tests were conducted on rock and concrete, not on soft soil.

\section{Discussion}

For a vertical free fall, the trend of the coefficients of restitution with increasing impact energy is the product of the trends observed for each of the parameters block mass and falling height. Consequently, for a certain block, the change in coefficients of restitution with impact energy is similar to the trend observed for the change of falling height (see the previous section). However, for blocks weighing $500 \mathrm{~kg}$ and more, which corresponds to higher impact energy levels, the previously-mentioned general decreasing trend of $R_{n}$ is found even slighter with a nearly constant value (Fig. 12). A similar observation is reported by Chau et al. (1998): they observe a decrease of $R_{n}$ with increasing impact energy for low energy levels, whereas for higher energy levels, the impact energy has no influence on $R_{n}$. The trends for $R_{t}$ and $R_{T E}$ are as well confirmed by the tests performed by Chau et al. (1998) or Wong et al. (2000).

The normal $\left(R_{n}\right)$, tangential $\left(R_{t}\right)$ and energetic $\left(R_{T E}\right)$ coefficients of restitution measured during the half-scale experimental study range between the following values:

$$
\begin{array}{llll}
R_{n}: & 0.003-0.257 & \text { mean over all tests: } & 0.04 \\
R_{t}: & 0.07-1 & \text { mean over all tests: } & 0.48 \\
R_{T E}: & 0.0003-0.336 & \text { mean over all tests: } & 0.03
\end{array}
$$

Figure 13 plots $R_{t}$ versus $R_{n}$ and compares the resulting variability range with data gathered from impact tests on detrital slopes by Fornaro et al. (1990) and with data from smallscale impact tests on soil slopes by Chau et al. (2002). Overall, the measured coefficients are found to meet quite well the values stated in literature for soft soil slopes. However, the presently obtained values for $R_{n}$ tend to be lower than the ones reported in some data sources (e.g. Fornaro et al., 1990). As these values are generally based on impact tests on soil slopes stiffer than the present slightly-compacted sand, this difference is understandable. It could also be due to differences in soil depths, i.e. the thickness of detrital material above bedrock in Fornaro et al. (1990) tests is possibly lower than the $1 \mathrm{~m}$ thickness of sand layer beneath the impact point imposed in the present half-scale study.

The wide range of variation of the coefficients of restitution, especially the tangential one, is related to the fact that they do not depend only on parameters related to the ground (stiffness and friction angle), but also on parameters related to the block and to the kinematics. As for the block 

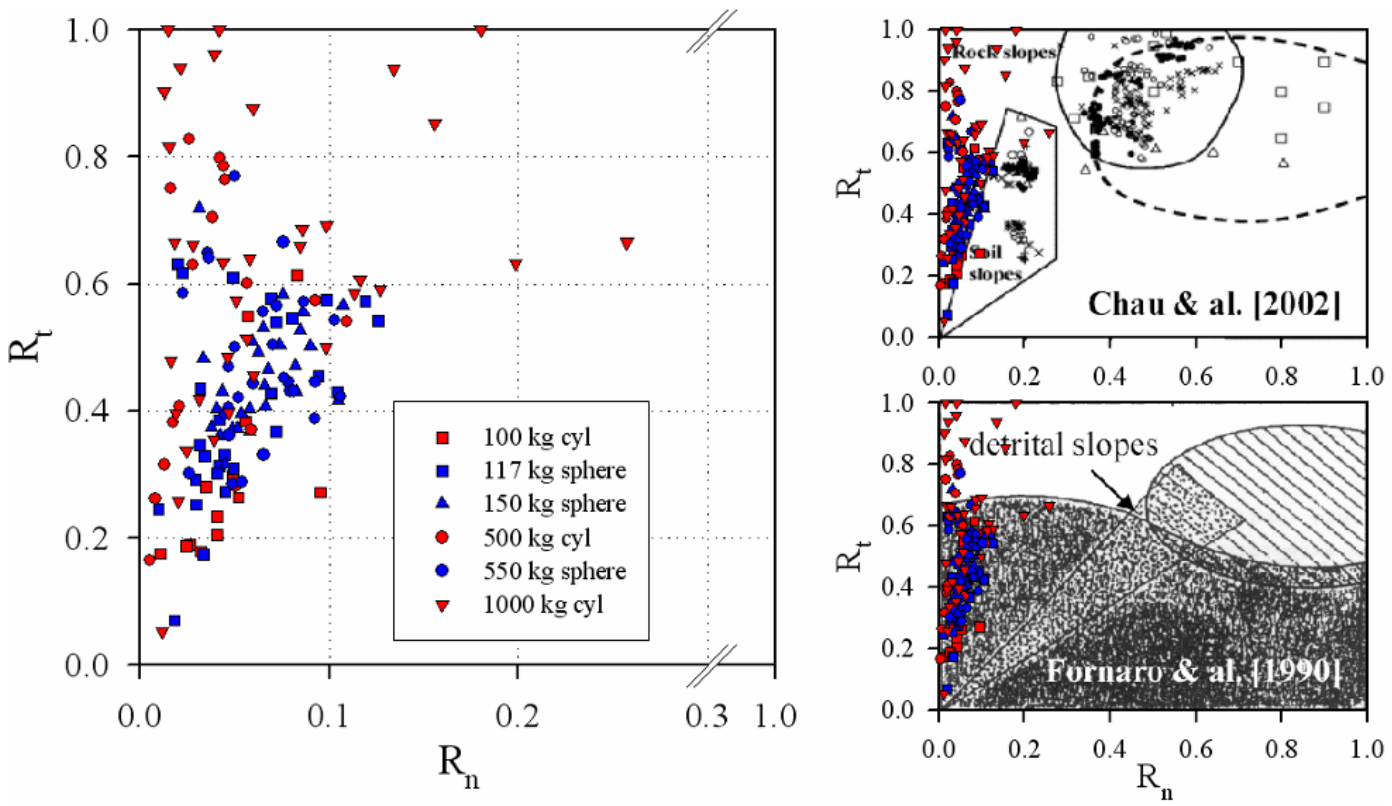

Fig. 13. Variability ranges of the coefficients of restitution $R_{n}$ and $R_{t}$ (without values for normal impacts) according to the half-scale test results (left, impact tests on a sandy slope). The variability ranges stated by Chau et al. (2002) and Fornaro et al. (1990) are presented on the right hand side.

characteristics (Sect. 3.3.2 and 3.3.3), the size and shape are found to have a stronger influence than the weight. A smaller block loses more energy during impact than a larger block with similar weight. This means that a boulder supposed to have e.g. an elliptical shape with a contact radius $R$ (flat side) and a contact radius $r$ (pointed side; with $R>r$ ) loses more energy during impact and rebounds less if it hits the ground with the more "pointed" part than if it impacts the ground with its flat side. As concerns the kinematics, the impact angle and the impact velocity, related respectively to the slope inclination and to the square root of the dropping height for the performed vertical free fall experiments, are found to have a clear influence as well, which confirms observations by Urciuoli (1988) and Pfeiffer and Bowen (1989).

From a thorough analysis of the impact films, the movement of the block is found to consist of three main mechanisms acting partly antagonistically:

- A normal translation (penetration), as a function of the bearing capacity of the ground material.

- A tangential translation (sliding), depending on the mass and shear resistance of the ground material in front of the block.

- A rotation of the block, as a function of the slope inclination, the impact direction and the impact velocity (by means of the depth of the crater generated during impact).
It is observed that these mechanisms are very much interdependent, as illustrated by the following four examples:

- For vertical impacts on horizontal ground, no rotation and lateral translation occur.

- For impacts of small incident velocity on a stable slope, i.e. not close its limit of equilibrium, no distinct crater is formed whereas the lateral translation and the rotation of the block are very clear. The ground behaves mainly elastically and the block rolls on the slope surface. This behaviour was observed for free falls of a few meters.

- For an impact of high velocity on the same slope, the block penetrates into the soft ground material, creating a distinct crater and causing local or even global failure of the ground. As the crater rim hinders the rolling of the block, the normal translation preponderates, whereas the lateral translation and the rotation are less clear.

- If the slope inclination is close to the internal friction angle of the ground material, the ground fails superficially at impact and causes a very distinct lateral movement of the block, whereas penetration and rotation are comparatively less important.

It has to be emphasised that the observations and statements made in the framework of this half-scale experimental study are valid for rather restrictive conditions, that is 
to say vertical impacts on a horizontal or inclined granular, cohesionless ground material (dry sand) at low energies (falling height $\leq 10 \mathrm{~m}$, block mass $\leq 1000 \mathrm{~kg}$ ) with spherical or spherical based blocks. The kinematical impact conditions (vertical fall on a slope, no initial rotation, high energy loss during impact resulting in low coefficients of restitution) correspond to the first impact of blocks detached from a steep rock face. It should be kept in mind that some of the described results might be influenced by the specific conditions of the performed tests and should be assessed for other impact conditions before generalisation. In particular, it was unfortunately not possible to distinguish the relative influence of the impact angle $\theta$ and of the slope inclination $\beta$ as they complete each other to $90^{\circ}$.

Concerning the block shape, it should be mentioned that some impact tests using a cubic block were performed within the scope of the research work. It has been shown that the impact configuration (e.g. impact on corner, toppling to face; impact on corner, toppling to edge; impact on edge, toppling to face) has a very important influence on the block movement during and after impact. The impact problem has been found to be three-dimensional, calling for a 3-D analysis of the phenomenon. Indeed, for certain configurations, the block topples to the side, leaving the image plan and rendering a 2-D analysis impossible.

The fact that it is necessary to consider the shape of the block and the kinematical conditions to describe the movement of the block during and after impact emphasises the complexity of the occurring mechanisms. Consequently, it is certainly illusive to model all different mechanisms occurring during the impact of rock blocks on granular material based on two overall coefficients of restitution as $R_{n}$ and $R_{t}$, expressing the rate of restituted velocity for the mass centre of the block. This simplification, actually adopted by most of the existing rockfall trajectory codes (lumped mass models), is certainly convenient but incapable of reproducing the impact phenomenon, especially on granular material. On the other hand, it is likely that the impact phenomenon could be better modelled by means of rigorous methods that take into account the shape of the blocks and use formulations with coefficients of restitution not defined for the mass centre of the block, but for the instantaneous contact surface between block and ground material.

As most trajectory computer codes model the block rebound by means of two restitution coefficients expressed for the mass centre of the block and generally only defined from a rough description of the outcropping material, their accuracy is certainly in question and their results should be interpreted with caution. For that reason, prior to any quantitative analysis of block trajectories, it is highly advisable to calibrate the program parameters on previous rockfall events on the site of interest or on other slopes with similar characteristics, by checking the trajectory results against field observations (impacts on the slope, damages to vegetation, zones of transit and accumulation). This advice was amongst the methodological recommendations asserted in an Interreg IIC project of the European Community entitled "Prevention of slope movements and cliff instabilities" (Labiouse et al., 2001; Labiouse, 2004).

\section{Conclusions}

In the framework of rockfall trajectory modelling, the bouncing phenomenon occurring when a rock block impacts with the slope surface is the most difficult to understand and to predict. To acquire a better knowledge of the phenomenon and to investigate the influence of various impact parameters, a comprehensive laboratory testing study was undertaken at the LMR-EPFL. The paper focuses on half-scale impact experiments (maximum energy of $100 \mathrm{~kJ}$ ) completed to quantify the coefficients of restitution. Blocks of different weights (up to $1000 \mathrm{~kg}$ ) and shape were vertically dropped from various heights (up to $10 \mathrm{~m}$ ) on a horizontal or inclined layer of slightly compacted sand (inclination up to $30^{\circ}$ ).

The analysis proves that the rebound of rock blocks as well as the coefficients of restitution expressed for the mass centre of the block, as commonly used to characterise the rebound in trajectory computer codes, depend not only on ground characteristics, but also on parameters related to the block and to the kinematics. As for the block characteristics, its size and shape are found to have a clear influence on the block motion and the coefficients of restitution. So it is for characteristics related to the kinematics such as the slope inclination and the impact velocity.

A thorough observation of the impacts has shown that the block motion during impact is governed by mechanisms of penetration, sliding and rotation, acting partly antagonistically. For different impact conditions, one or another of these mechanisms is privileged, governing on its part the block motion after impact.

The complexity of the rebound process emphasizes that it is not adequate to model it by means of two overall coefficients of restitution expressed for the mass centre of the block. Models that take into consideration the instantaneous contact surface between block and ground material should be more appropriate. As the former approach is adopted for convenience by many rockfall trajectory codes, computer results should always be checked against field observations prior to any delineation of areas at risk and design of protection measures.

Acknowledgements. The authors thank the Swiss National Science Foundation (grant No 21-57128.99) and the LMR-EPFL for supporting the thesis financially. They are also grateful to two reviewers, whose suggestions and comments have helped to improve the quality of the paper.

Edited by: K. Schellenberg

Reviewed by: M. Thuering and another anonymous referee 


\section{References}

Azimi, C., Desvarreux, P., Giraud, A., and Martin-Cocher, J.: Méthode de calcul de la dynamique des chutes de blocs - Application à l'étude du versant de la montagne de La Pale (Vercors), Bulletin de liaison des laboratoires des ponts et chaussées, Paris, 122, 93-102, 1982.

Azzoni, A. and Freitas, M. H.: Experimentally Gained Parameters, Decisive for Rock Fall Analysis, Rock Mech. Rock Eng., 28(2), 111-124, 1995.

Barbieri, G., Giani, G. P., Uras, G., and Vernier, A.: Modellizzazione della frana di crollo di Monte Oili in agro di Baunei (Nuoro), presented at the Riunione Plenaria delle Unita Operative del CNR, Roma, 19-20 December, 1988.

Bozzolo, D. and Pamini, R.: Simulation of Rock Falls down a Valley Side, Acta Mech., 63, 113-130, 1986.

Chau, K. T., Chan, L. C. P., Wu, J. J., Liu, J., Wong, R. H. C., and Lee, C. F.: Experimental studies on rockfall and debris flow, in: Proc. Seminar on Planning, Design and Implementation of Debris Flow and Rockfall Hazards Mitigation Measures, Hong Kong, 115-128, 1998.

Chau, K. T., Wong, R. H. C., Liu, J., Wu, J. J., and Lee, C. F.: Shape effects on the coefficient of restitution during rockfall impacts, in Proc. 9th Int. Congress on Rock Mechanics, ISRM, Paris, 1, 541-544, 1999a.

Chau, K. T., Wu, J. J., Wong, R. H., and Lee, C. F.: The coefficient of restitution for boulders falling onto soil slopes with various values of dry density and water content, in: Proc. Int. Symp. on Slope Stability Engineering: Geotechnical and Geoenvironmental Aspects, Matsuyama, Shikoku, Japan, 2, 1355-1360, 1999 b.

Chau, K. T., Wong, R. H. C., and Wu, J. J.: Coefficient of restitution and rotational motions of rockfall impacts, Int. J. Rock Mech. Min., 39, 69-77, 2002.

Dorren, L. K. A., Berger, F., and Putters, U. S.: Real-size experiments and 3-D simulation of rockfall on forested and nonforested slopes, Nat. Hazards Earth Syst. Sci., 6, 145-153, 2006, http://www.nat-hazards-earth-syst-sci.net/6/145/2006/.

Falcetta, J. L.: Un nouveau modèle de calcul de trajectoires de blocs rocheux, Revue Française de Géotechnique, Paris, 30, 11-17, 1985.

Fornaro, M., Peila, D., and Nebbia, M.: Block falls on rock slopes - application of a numerical simulation program to some real cases, in: Proc. 6th Int. Congress IAEG, Rotterdam, 2173-2180, 1990

Gerber, W.: Auswertung von Feldversuchen, in: Unterlagen zum FAN-Kurs der Forstlichen Gruppe Naturgefahren zum Thema "Steinschlag", Vitznau, Kap. 9, 1995.

Giani, G. P.: Rock Slope Stability Analysis, Balkema, Rotterdam, 361 pp., 1992.

Heidenreich, B.: Small- and half scale experimental studies of rockfall impacts on sandy slopes, Swiss Federal Institute of Technology Lausanne, Ph.D. thesis No 3059, 2004.
Heidenreich, B. and Labiouse, V.: Small-scale laboratory experiments of boulders bouncing on granular slopes, in: Proc. 10th Int. Congress on Rock Mechanics, ISRM, Johannesburg, 1, 519522, 2003.

Heidenreich, B. and Labiouse, V.: Small-scale experimental study of rockfall impacts on granular slopes, Rivista Italiana di Geotecnica, Anno XXXVIII, no 2, 80-91, 2004.

Hungr, O. and Evans, S. G.: Engineering evaluation of fragmental rockfall hazards, in: Proc. 5th Int. Symposium on Landslides, Lausanne, 1, 685-690, 1988.

Hutchings, I. M., Macmillan, N. H., and Rickerby, D. G.: Further studies of the oblique impact of a hard sphere against a ductile solid, Int. J. Mech. Sci., 23(11), 639-646, 1981.

Labiouse, V.: Fragmental rockfall paths: comparison of simulations on Alpine sites and experimental investigation of boulder impacts, in: Proc. 9th Int. Symposium on Landslides, Rio, 1, 457-466, 2004.

Labiouse, V. and Descoeudres, F.: Possibilities and Difficulties in predicting Rockfall Trajectories, Proc. of the Joint Japan-Swiss Scientific Seminar on Impact Load by Rock Falls and Design of Protection Structures, Kanazawa, Japan, 29-36, 1999.

Labiouse, V., Descoeudres, F., and Montani, S.: Experimental Study of Rock Sheds Impacted by Rock Blocks, Structural Engineering International, 3/96, 171-176, 1996.

Labiouse, V., Heidenreich, B., Desvarreux, P., Viktorovitch, M., and Guillemin, P.: Etudes trajectographiques, in: Programme Interreg IIc - "Falaises", Prévention des mouvements de versants et des instabilités de falaises, edited by: Carere, K., Ratto, S., and Zanolini, Aosta, 155-211, 2001.

Montani Stoffel, S.: Sollicitation dynamique de la couverture des galeries de protection lors de chutes de blocs, Swiss Federal Institute of Technology Lausanne, Ph.D. thesis No 1899, 1998.

Pfeiffer, T. and Bowen, T.: Computer Simulation of Rockfalls, Bulletin of the Association of Engineering Geologists, 26(1), 135$146,1989$.

Stevens, W. D.: RocFall: a tool for probabilistic analysis, design of remedial measures and prediction of rockfalls, University of Toronto, Master thesis, 1998.

Urciuoli, G.: Sperimentazione sulla caduta di blocchi lungo un pendio nella formazione calcareo-dolomitica della Penisola Sorrentina, in: Proc. Convengo Cartografia e monitoraggio dei movimenti franosi, Bologna, 35-54, 1988.

Ushiro, T., Shinohara, S., Tanida, K., and Yagi, N.: A study on the motion of rockfalls on slopes, in: Proc. 5th Symposium on Impact Problems in Civil Engineering, Japan Society of Civil Engineers, 91-96, 2000.

Wong, R. H., Ho, K. W., and Chau, K. T.: Shape and mechanical properties of slope material effects on the coefficient of restitution on rockfall study, in: Proc. 4th North American Rock Mechanics Symposium NARMS 2000, Seattle, 507-514, 2000.

Wu, S. S.: Rockfall evaluation by computer simulation, Transportation Research Record 1031, 1-5, Washington, 1985. 